\title{
High-throughput targeted SNP discovery using Next Generation Sequencing (NGS) in few selected candidate genes in Eucalyptus camaldulensis
}

\author{
Prasad Suresh Hendre*, Rathinam Kamalakannan, Rathinavelu Rajkumar, Mohan Varghese \\ From IUFRO Tree Biotechnology Conference 2011: From Genomes to Integration and Delivery \\ Arraial d'Ajuda, Bahia, Brazil. 26 June - 2 July 2011
}

\section{Background}

The present era of high throughput technologies offer immense promise and innovative applications for SNP discovery and high quality parallel genotyping [1,2]. Using advancements in the next generation sequencing (NGS) technologies, the en masse SNP discovery for targeted genomic regions is possible for eucalypts. The river red gum or Eucalyptus camaldulensis $(E c)$ is a fast growing, hardy and highly adaptable eucalypt species acclimatized to Indian climatic conditions and these new advancements would aid in developing new tools and techniques for its improvement. In our knowledge, limited efforts have been undertaken to identify SNP markers in eucalypts either by employing RNA sequencing [3] or by using few genes available in the literature [4]. Despite these miniscule efforts, useful SNP markers were discovered in Cinnamoyl CoA Reductase (CCR) gene with potential application [5]. Using the recently released whole genome sequence of $E$. grandis ( $E g)$, herein we describe targeted SNP discovery in 41 candidate genes by employing Illumina's 72-bases paired end sequencing technology.

\section{Materials and methods}

The DNA was isolated from a SNP discovery panel consisting 96 individuals from a naturally mating $E c$ population from Australia following standard procedures (modified CTAB method). Twelve primary DNA pools were constituted by mixing equimolar concentrations of eight DNAs @ 10 ng/mL. Forty one genes selected for

\footnotetext{
* Correspondence: prasad.hendre@itc.in

ITC R\&D Centre, Peenya Insdustrial Area, No.3, 1st Main, 1st Phase, Bangalore- 560 058, Karnataka, India
}

SNP discovery were identified from $E g$ genome (http:// eucalyptusdb.bi.up.ac.za/gbrowse8x) by employing Arabidopsis TAIR 9 gene IDs. Further the primer pairs were designed to amplify the gene fragments. The individual primary DNA pool was amplified (Veriti-ABI) using Paq DNA polymerase (Agilent Technologies), all amplicons pooled (figure 1), eluted if necessary ( $E c$ CREAHK4, Ec OBP1), precipitated using ethanol and dissolved in TE (0.1).

A paired end library suitable for 72-bases read length was prepared and sequenced on an Illumina GAIIx sequencer and analyzed using bwa and samtools with appropriate parameters (outsourced to Genotypic Technologies Ltd, Bangalore). The SNP data was adjusted for read depth $\left(1 / 10^{\text {th }} \mathrm{SD}\right)$ and rare allele frequency $(<5 \%)$. Further approximate equal frequency (EF) blocks were manually estimated by nearest neighborhood (NN) analysis in MS Excel (MS Office 2007), wherein, a block of NN SNPs having frequency difference of less than 0.020.03 was considered as single EF block. Web-based gene prediction tool FGENESH (http://linux1.softberry.com) was used for identifying genic regions such as UTRs, exons and introns with Arabidopsis thaliana gene model.

\section{Results and discussion}

Forty one growth and adaptive genes were selected based on literature search [6, TAIR database]. A total of $100.5 \mathrm{~kb}$ genomic sequence from $E c$ genome spread over $\sim 1055 \mathrm{Mbp}$ reads was generated ( $\sim 94 \%$ high quality reads with average read depth 6124$)$. A total of 11,329 SNPs were polymorphic within $E c$ and 378 SNPs exhibited inter-species polymorphism between $E c$ and 


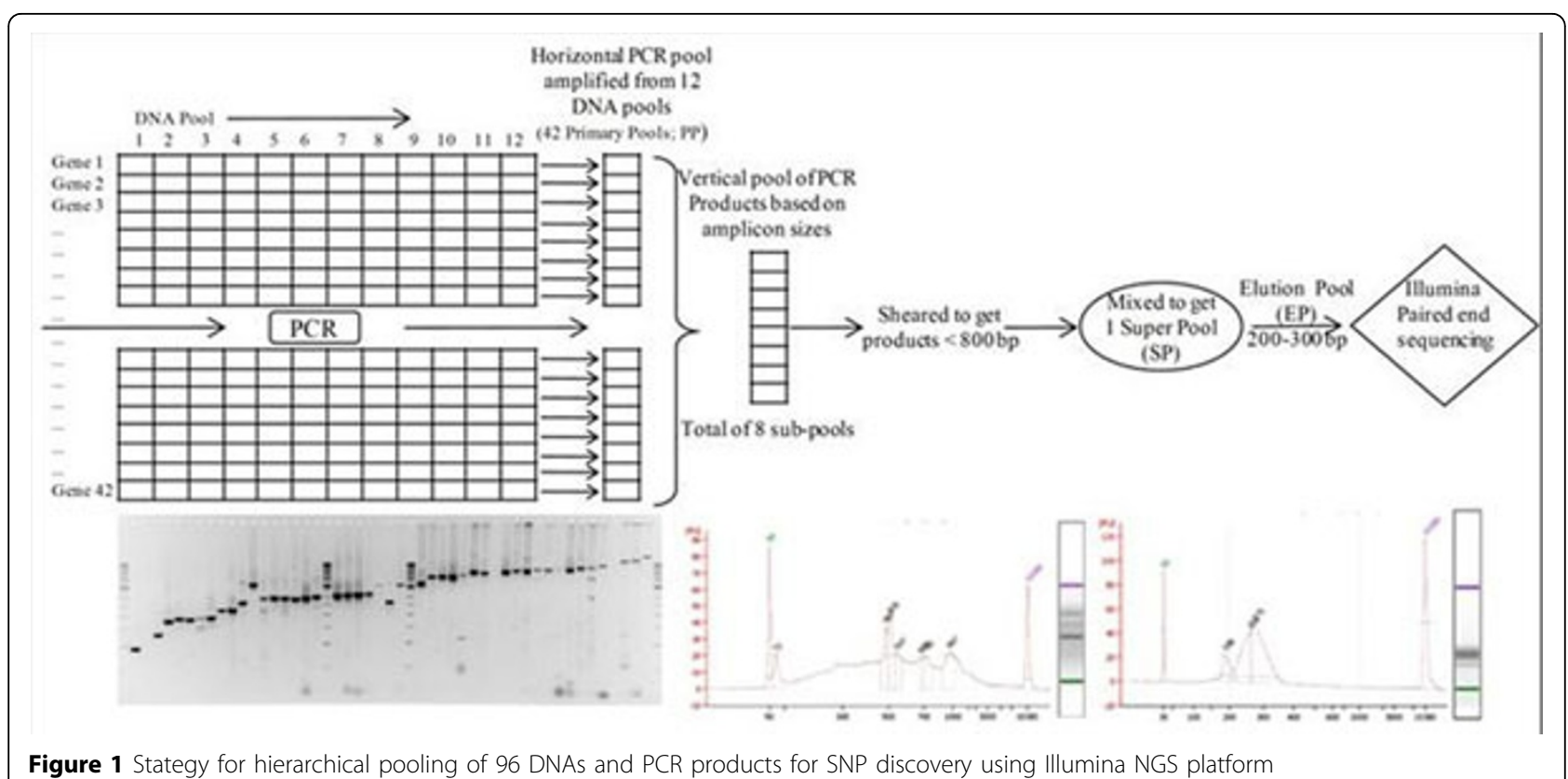

Table 1 Results from SNP discovery in 41 candidate genes.

\begin{tabular}{|c|c|c|c|c|c|c|c|}
\hline \multirow[t]{2}{*}{ Predicted gene region } & \multicolumn{3}{|c|}{ SNP frequency parameters } & \multicolumn{3}{|c|}{ SNP classification } & \multirow[b]{2}{*}{ Ratio(Ts/Tv } \\
\hline & SNP count (range) & SNP Frequency in bases/SNP (range) & Total length in bp (range) & $T s$ & $T v$ & Total & \\
\hline $5^{\prime} U T R(n=1)$ & 4 & 40.8 & 163 & 1 & 3 & 4 & 0.33 \\
\hline $\operatorname{Exons}(n=176)$ & $427(1-52)$ & $105.8(0-1339)$ & $45,177(200-3487)$ & 310 & 117 & 427 & 2.65 \\
\hline Introns $(n=136)$ & $536(0-64)$ & $71.3(0-472)$ & $38,210(68-5079)$ & 332 & 204 & 536 & 1.63 \\
\hline $3^{\prime} U T R(n=27)$ & $54(0-11)$ & $81.6(0-358)$ & $4,405(7-674)$ & 33 & 21 & 54 & 1.57 \\
\hline Unclassified $(n=13)$ & $69(0-25)$ & $62.7(0-425)$ & $4,329(4-425)$ & 40 & 29 & 69 & 1.38 \\
\hline Nongenic $(n=17)$ & $101(0-25)$ & $82.6(0-974)$ & $8,340(6-1481)$ & 63 & 38 & 101 & 1.66 \\
\hline Total $(n=370)$ & $1,191(1-115)$ & $84.5(38.2-974)$ & $100,624(634-9864)$ & 779 & 412 & 1191 & 1.89 \\
\hline
\end{tabular}

Note: $n$ : number of units detected from 41 genes; Ts: transitions, Tv: transversions

$E g$. In addition, 75 insertions and 90 deletions within $E c$ and eight intra-specific deletions in comparison to $E g$ were detected. After appropriate corrections as described, the 'useful' SNP number reduced to 1,191 which was $\sim 10.5 \%$ of the original SNP count ( frequency of 1 per $84.5 \mathrm{bp}$ ). Table 1 describes findings from the present analysis of SNPs. A total of 198 putative EF blocks containing 541 SNPs, grossly comparable to LD blocks, with 55, 65 and 34 in exons, introns, exon-intron junctions respectively were detected (rest all were small in numbers) with an average length of $\sim 105$ bp (SD: \pm 182 ; range: $1-1234$ bp, distribution shown in figure 2; 3 SNPs/block) and would aid in selection of SNPs. The comparable mean lengths adjusted for the respective amplicon lengths were around 0.014 to 0.016 (SD: \pm 0.013 to \pm 0.015 ) for exons, introns and nongenic

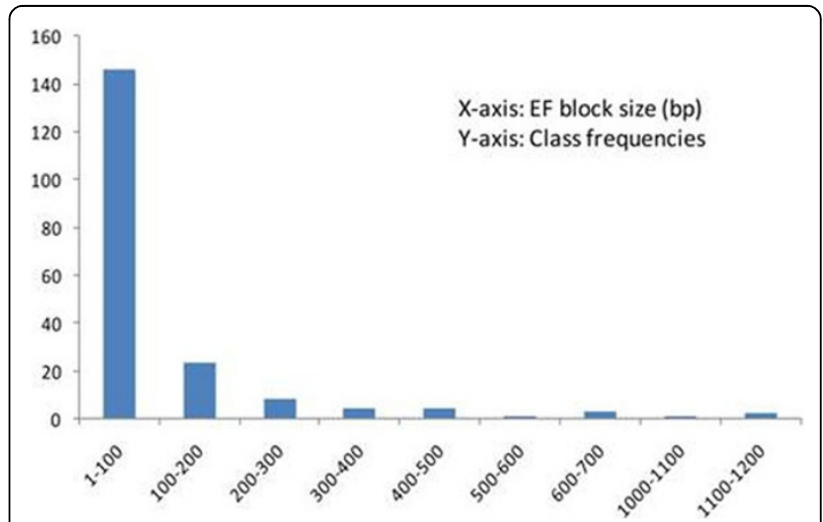

Figure 2 Bar graph showing distribution of 198 frequency (EF) blocks according to their length (bp) 
regions whereas for intron-exon junctions it was 0.028 \pm 0.023 , significantly longer than the rest $(\mathrm{p}=0.03)$.

\section{Conclusions}

Herein, NGS (Illumina) platform was successfully used for identifying 1,200 SNPs in 41 targeted genes in $E c$ which has shed important light on quantitative and qualitative distribution of SNPs. In addition, the analysis of EF blocks also provided important guidelines for selection of SNPs for genotyping.

\section{Acknowledgements}

The authors acknowledge valuable discussions with Dr. Navin Sharma, Dr. DS Gurumurthy, (both ITC R\&D Centre, Bangalore, India) and Dr. BR Thumma, Dr. Simon Southerton, (both CSIRO-Plant Industry, Canberra, Australia) and also the Eucagen website (http://eucalyptusdb.bi.up.ac.za/gbrowse8x) for making the Eg sequence available.

Published: 13 September 2011

\section{References}

1. Rafalski A: Applications of single nucleotide polymorphisms in crop genetics. Curr Opin Plant Biol 2002, 5:94-100.

2. Perkel J: SNP genotyping: six technologies that keyed a revolution. Nature Methods 2008, 5:447-454.

3. Novaes E, Drost DR, Farmerie WG, Pappas GJ Jr, Grattapaglia D, Sederoff RR, Kirst M: High-throughput gene and SNP discovery in Eucalyptus grandis, an uncharacterized genome. BMC Genomics 2008, 9:312.

4. Kulheim C, Yeoh SH, Maintz J, Foley WJ, Moran GF: Comparative SNP diversity among four Eucalyptus species for genes from secondary metabolite biosynthetic pathways. BMC Genomics 2009, 10:452.

5. Thumma BR, Nolan MF, Evans R, Moran GF: Polymorphisms in Cinnamoyl CoA Reductase (CCR) are associated with variation in microfibril angle in Eucalyptus spp. Genetics 2005, 171:1257-1265.

6. Busov VB, Brunner AM, Strauss SH: Genes for control of plant stature and form. New Phytologist 2008, 177:589-607.

doi:10.1186/1753-6561-5-S7-017

Cite this article as: Hendre et al.: High-throughput targeted SNP discovery using Next Generation Sequencing (NGS) in few selected candidate genes in Eucalyptus camaldulensis. BMC Proceedings 20115 (Suppl 7):017.

\section{Submit your next manuscript to BioMed Central} and take full advantage of:

- Convenient online submission

- Thorough peer review

- No space constraints or color figure charges

- Immediate publication on acceptance

- Inclusion in PubMed, CAS, Scopus and Google Scholar

- Research which is freely available for redistribution

Submit your manuscript at www.biomedcentral.com/submit 